\title{
Characterization of antibiotic resistance in commensal bacteria from an aquaculture ecosystem
}

\section{OPEN ACCESS}

Edited by:

Gillberto Igrejas,

University of Trás-os-Montes and Alto

Douro, Portugal

Reviewed by:

Magdalena Popowska, University of Warsaw, Poland

Carmen Losasso,

Istituto Zooprofilattico Sperimentale delle Venezie, Italy

*Correspondence:

Hua H. Wang,

Department of Food Science and Technology, The Ohio State

University, 2015 Fyffe Court,

Columbus, OH 43210, USA wang.707@osu.edu

Specialty section:

This article was submitted to Antimicrobials, Resistance and Chemotherapy,

a section of the journal

Frontiers in Microbiology

Received: 29 May 2015

Accepted: 20 August 2015

Published: 08 September 2015

Citation:

Huang Y, Zhang L, Tiu L and Wang HH (2015) Characterization of antibiotic resistance in commensal bacteria from an

aquaculture ecosystem.

Front. Microbiol. 6:914. doi: 10.3389/fmicb.2015.00914

\section{Ying Huang', Lu Zhang', Laura Tiu² and Hua H. Wang ${ }^{1,3,4 *}$}

1 Department of Food Science and Technology, The Ohio State University, Columbus, OH, USA, ${ }^{2}$ South Centers, The Ohio State University, Piketon, OH, USA, ${ }^{3}$ Department of Microbiology, The Ohio State University, Columbus, OH, USA, ${ }^{4}$ School of Biological Sciences, Fudan University, Yangpu, Shanghai, China

The objective of the study was to improve the understanding of antibiotic resistance (AR) ecology through characterization of antibiotic-resistant commensal isolates associated with an aquaculture production system. A total of 4767 isolates non-susceptible to sulfamethoxazole/trimethoprim (Sul/Tri), tetracycline (Tet), erythromycin (Erm), or cefotaxime (Ctx), originated from fish, feed, and environmental samples of an aquaculture farm with no known history of antibiotic applications were examined. Close to $80 \%$ of the isolates exhibited multi-drug resistance in media containing the corresponding antibiotics, and representative AR genes were detected in various isolates by PCR, with feed isolates had the highest positive rate detected. Identified AR gene carriers involved 18 bacterial genera. Selected AR genes led to acquired resistance in other bacteria by transformation. The AR traits in many isolates were stable in the absence of selective pressure. AR-rich feed and possibly environmental factors may contribute to $A R$ in the aquaculture ecosystem. For minimum inhibitory concentration test, brain heart infusion medium was found more suitable for majority of the bacteria examined than cation-adjusted Mueller Hinton broth, with latter being the recommended medium for clinical isolates by standard protocol. The data indicated a need to update the methodology due to genetic diversity of microbiota for better understanding of the AR ecology.

Keywords: antibiotic resistance, aquaculture ecosystem, multiple risk factors, commensal bacteria

\section{Introduction}

The rapid emergence of antibiotic resistance (AR) in the global ecosystem has become a major public health concern. In the past decade, with a broadened scope of investigation, both population- and organism-based studies have illustrated that commensal bacteria likely have played a key role in AR ecology (Andremont, 2003; Wang et al., 2006; Wang and Schaffner, 2011). With the expansion of research territory, AR has been found prevalent across the ecosystem, from clinical samples, animal and human hosts, retail foods, to waste water, soil, and other natural environment (Zhanel et al., 2000; Österblad et al., 2001; Aubry-Damon et al., 2004; Wang et al., 2006; Koike et al., 2007; Sommer et al., 2009; Li and Wang, 2010; D'Costa et al., 2011; Zhang, 2011; Ye et al., 2013). For instance, using non-specific culturing methods and culture-independent real-time PCR, the abundance of AR in the food chain was revealed and a broad-spectrum of 
non-pathogenic and even beneficial bacteria were found carrying transmissible AR genes (Duran and Marshall, 2005; Wang et al., 2006; Manuzon et al., 2007). Characterization of antibioticresistant (ART) isolates associated with food animals, readyto-eat food products, human, and environmental samples has led to the discovery of various mechanisms involved in AR evolution (Sommer et al., 2009; Bhullar et al., 2012), enrichment (Zhang et al., 2011), and persistence (Sørum et al., 2006; Rosvoll et al., 2010; Li et al., 2011). It becomes evident that commensal flora provides a particular window of vulnerability of AR in the ecosystem, and prompt response to the early indication can be critically important for preventive AR management (Andremont, 2003; Wang et al., 2006; Wang and Schaffner, 2011). Due to the advancement in metagenomics and other molecular techniques, the complexity of microbiome associated with both hosts and environment has been gradually uncovered (Venter et al., 2004; Sommer et al., 2009; Zhang et al., 2011). However, the extremely large size and diverse distribution of the commensal population, as well as genetic diversity of the subpopulations presented several major challenges to researchers. There is no single way of recovering, culturing, or characterizing all the cultures, making proper interpretation of data a daunting task.

Aquatic creatures are susceptible to infectious diseases. Use of antibiotics in aquaculture production systems is considered a major risk factor contributing to $\mathrm{AR}$ in aquaculture products and the ecosystem. ART pathogens, such as Aeromonas (Akinbowale et al., 2007; Penders and Stobberingh, 2008), Vibrio (Oh et al., 2011; Rebouças et al., 2011), and Salmonella (Ribeiro et al., 2010; Budiati et al., 2013), have been reported to be associated with the aquaculture system. Particularly, certain AR determinants have been found in both aquaculture and clinical isolates, indicating potential AR dissemination between food and humans. For instance, one gene cassette containing bla $a_{\mathrm{CMY}-2}$, sugE, and blc detected in Aeromonas salmonicida ssp. salmonicida isolates from Atlantic Canadian salmon farm was identical to a transponson-like element widely distributed among clinical and food-borne Salmonella and other Enterobacteriaceae throughout Asia and the United States (McIntosh et al., 2008). Rhodes et al. (2000) reported the dissemination of tet(A)-associated Tn1721 and Tn1721-like elements among different Aeromonas species and Escherichia coli, and between the human and aquaculture environment in distinct geographical locations (including Norway, Scotland, England, and Germany). In addition, various AR genes were found in a broad spectrum of commensal bacteria associated with aquaculture products and the environment (Ye et al., 2013; Shah et al., 2014). However, these data are still insufficient in elucidating $\mathrm{AR}$ risk factors in the aquaculture ecosystem.

In a recent study, we have uncovered a rich profile of ART bacteria in samples from a domestic aquaculture farm with no known history of antibiotic application, by culture-dependent and -independent methods (Huang, 2014). The objective of this study was to characterize the genotypic and phenotypic features of the corresponding ART isolates, as well as AR persistence and dissemination, for an improved understanding of the AR ecology associated with aquaculture production. During the evaluation of minimum inhibitory concentration (MIC) for representative antibiotics of the isolates, we have compared the data using both standard approach for pathogens (CLSI, 2013) and a modified method (Wang et al., 2006), to collect baseline information for further methodology improvement, to address the needs for proper assessment of commensal bacteria.

\section{Materials and methods}

\section{Bacterial Strains and Culture Condition}

A total of 4767 isolates recovered from Sul/Tri-, Tet-, Erm-, or Ctx-containing agar plates were examined in the study. These isolates originated from fish intestine (1045 isolates), fish surface rinsing water (850 isolates), fish feed (150 isolates), pond mud (1293 isolates), and pond water (1429 isolates) from an aquaculture farm with no known history of antibiotic applications. All isolates were cultured in brain heart infusion (BHI) media containing the corresponding antibiotics, including $152 \mu \mathrm{g} / \mathrm{ml}$ of sulfamethoxazole (Sigma-Aldrich, St. Louis, MO, USA) with $8 \mu \mathrm{g} / \mathrm{ml}$ of trimethoprim (Sigma-Aldrich), $16 \mu \mathrm{g} / \mathrm{ml}$ of tetracycline (Sigma-Aldrich), $100 \mu \mathrm{g} / \mathrm{ml}$ of erythromycin (Fisher Scientific, Waltham, MA, USA), or $4 \mu \mathrm{g} / \mathrm{ml}$ of cefotaxime (Sigma-Aldrich; Ye et al., 2013).

\section{Determination of Drug Resistance Profiles, AR Genes, and Identification of AR Gene Carriers}

Recovered Sul/ $\operatorname{Tri}^{r}, \operatorname{Tet}^{r}, \operatorname{Erm}^{r}$, and $\mathrm{Ctx}^{\mathrm{r}}$ isolates were spotted on $\mathrm{BHI}$ agar plates containing each of the four antibiotics for rapid assessment of their phenotypic resistance profile.

Approximately one-fourth of the ART isolates were randomly selected for conventional PCR screening for representative AR genes (Li and Wang, 2010). AR gene primers used in the study were listed in Table 1. Approximately $10 \%$ of the positive PCR products were confirmed by DNA sequence assessment using an ABI Prism 3700 sequencer (Applied Biosystems, Foster City, CA, USA) at the Plant Microbe Genomics Facility, The Ohio State University, and the obtained DNA sequences were compared with published AR gene sequences deposited in the NCBI database. Approximately $50 \%$ of the AR gene carriers were further identified by PCR and partial 16S rRNA gene sequence analysis, as described previously (Wang et al., 2006).

\section{MIC Assessments}

Twenty-nine ART isolates carrying AR genes were subjected to the MIC test. The assessments were conducted using microbroth dilution method as suggested by CLSI (2013) protocol. BHI and cation-adjusted Mueller Hinton (CAMH) broth were employed as basic medium independently. ART isolates were grown in the broth containing the corresponding antibiotic (including up to $608 \mu \mathrm{g} / \mathrm{ml} \mathrm{Sul} \mathrm{with} 32 \mu \mathrm{g} / \mathrm{ml}$ Tri, $512 \mu \mathrm{g} / \mathrm{ml}$ Tet, $512 \mu \mathrm{g} / \mathrm{ml}$

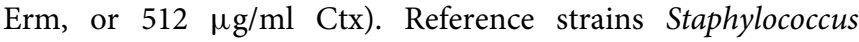
aureus ATCC $^{\circledR} 29213$, Enterococcus faecalis ATCC ${ }^{\circledR} 29212$, E. coli ATCC ${ }^{\circledR} 25922$, and Pseudomonas aeruginosa ATCC ${ }^{\circledR} 27853$ were examined in parallel as controls. 
TABLE 1 | Primers used for conventional PCR.

\begin{tabular}{|c|c|c|}
\hline Primer & Sequence $\left(5^{\prime}-3^{\prime}\right)$ & Reference \\
\hline sul1 $\mathrm{F}$ & CGGCGTGGGCTACCTGAACG & Kerrn (2002) \\
\hline sul1 R & GCCGATCGCGTGAAGTTCCG & \\
\hline sul2 F & GCAGGCGCGTAAGCTGA & Zhang et al. (2011) \\
\hline sul2 R & GGCTCGTGTGTGCGGATG & \\
\hline tets F & GAACGCCAGAGAGGTATT & Zhang et al. (2011) \\
\hline tetS R & TACCTCCATITGGACCTCAC & \\
\hline tetL F & TTGGATCGATAGTAGCC & Zhang et al. (2011) \\
\hline tetL R & GTAACCAGCCAACTAATGAC & \\
\hline tetM F & CGAACAAGAGGAAAGCATAAG & Zhang et al. (2011) \\
\hline tetM R & CAATACAATAGGAGCAAGC & \\
\hline ermB F & TGGTATTCCAAATGCGTAATG & Zhang et al. (2011) \\
\hline ermB R & CTGTGGTATGGCGGGTAAGT & \\
\hline erm C F & GCTAATATTGTTTAAATCGTCAAT & Wang et al. (2006) \\
\hline ermC R & TCAAAACATAATATAGATAAA & \\
\hline bla TEM $_{\text {T }} F$ & САTTTCCGTGTCGCCCTTATTC & Dallenne et al. (2010) \\
\hline bla TEM $R$ & CGTTCATCCATAGTTGCCTGAC & \\
\hline blasHv F & AGCCGCTTGAGCAAATTAAAC & Dallenne et al. (2010) \\
\hline blasHv $\mathrm{R}$ & ATCCCGCAGATAAATCACCAC & \\
\hline blaoxA F & GGCACCAGATTCAACTTTCAAG & Dallenne et al. (2010) \\
\hline blaoxa $R$ & GACCCCAAGTTTCCTGTAAGTG & \\
\hline blacмY $-2 \mathrm{~F}$ & GACAGCCTCTTTCTCCACA & Zhang et al. (2011) \\
\hline blacmY -2 R & TGGAACGAAGGCTACGTA & \\
\hline blactхмu1 & ATGTGCAGYACCAGTAARGT & Zhang et al. (2011) \\
\hline blactX MU2 & TGGGTRAARTARGTSACCAGA & \\
\hline
\end{tabular}

\section{Persistence of AR}

AR stability in resistant isolates was determined according to the published procedures (Li et al., 2011) with slight modifications. Basically, after consecutive transfer every $12 \mathrm{~h}$ for 30 days, the cultures were serially diluted and plated on BHI agar plates. One hundred colonies were randomly picked from each sample, and spotted onto $\mathrm{BHI}$ agar plates with and without the corresponding antibiotic. The ratio of resistant to total colonies was used to describe the resistance persistence in ART isolates at the absence of the antibiotic selective pressure.

\section{Transformation}

Chemical transformation was conducted using plasmids from nine Gram-negative ART isolates carrying AR genes and E. coli $\mathrm{DH} 5 \alpha$ as a recipient by the calcium chloride transformation method (Dagert and Ehrlich, 1979). Meanwhile, electroporation was employed when introducing plasmids from five Grampositive ART isolates carrying AR genes to Lactococcus lactis LM 2301 following the procedures described previously (Mcintyre and Harlander, 1989).

\section{Results}

\section{MIC Assessment}

MIC analysis showed that the MIC results of Tet, Erm, or Ctx for the four reference strains were comparable in $\mathrm{BHI}$ and $\mathrm{CAMH}$ broth. However, culture medium had varied but clear impact on MIC results of Sul/Tri. For instance, while the MIC values of Sul/Tri for $P$. aeruginosa ATCC ${ }^{\circledR} 27853$ in both media were comparable $(608 / 32 \mu \mathrm{g} / \mathrm{ml})$, the other three reference strains showed 4- to 64-fold higher MIC values in BHI than that of in CAMH. It is worth noting that E. faecalis ATCC ${ }^{\circledR} 29212$ didn't grow as well in CAMH as in BHI broth.

As illustrated in Table 2, twenty-nine isolates used in the MIC assessment were identified and they belonged to 15 genera. MIC values for Tet, Erm, or Ctx in BHI were the same as, or twofold to fourfold higher than the results from CAMH. Among the strains examined, 9 out of $20(45 \%) \mathrm{Ter}^{\mathrm{r}}, 6$ out of $6(100 \%) \mathrm{Erm}^{\mathrm{r}}$, and 2 out of $5(40 \%) \mathrm{Ctx}^{\mathrm{r}}$ isolates exhibited high and consistent MIC values (no less than $128 \mu \mathrm{g} / \mathrm{ml}$ ) in both $\mathrm{BHI}$ and $\mathrm{CAMH}$ for Tet, Erm, or Ctx, respectively. But the MIC values for Sul/Tri in BHI and CAMH varied significantly in close to $70 \%$ of the isolates (21 out of 29). Some Sul/Tri ${ }^{\mathrm{r}}$ isolates showed very high value (no less than $608 / 32 \mu \mathrm{g} / \mathrm{ml}$ ) in both BHI and CAMH, including Plesiomonas sp., Aeromonas sp., and Psychrobacter sp. Bacteria from genera such as Enterobacter sp., Bacillus sp., and Kurthia sp. showed higher MIC value in BHI (no less than 304/16 $\mu \mathrm{g} / \mathrm{ml}$ ) than that in CAMH (no more than 9.5/0.5 $\mu \mathrm{g} / \mathrm{ml}$ ). Moreover, isolates of Vagococcus sp., Aerococcus sp., Corynebacterium sp., and Enterococcus sp. didn't grow or had poor growth in $\mathrm{CAMH}$, but exhibited higher MIC value in BHI (no less than $608 / 32 \mu \mathrm{g} / \mathrm{ml})$.

\section{Phenotypic-Resistant Profiles of the ART Isolates}

Of the recovered Sul/Trir ${ }^{\mathrm{r}}, \mathrm{Tet}^{\mathrm{r}}, \mathrm{Erm}^{\mathrm{r}}$, and $\mathrm{Ctx}^{\mathrm{r}}$ isolates (from BHI plates) associated with fish intestine, surface rinsing water, fish feed, pond mud, and pond water samples, 3772 of 4767 total isolates $(79.1 \%)$ showed resistance to more than one antibiotic, and 824 isolates $(17.4 \%)$ were resistant to all four antibiotics tested. As shown in Table 3, multi-drug-resistant bacteria were common in all samples.

\section{Prevalence of the AR Genes and Identification of the Isolates}

As shown in Table 4, more AR genes were detected in isolates associated with fish feed and fish intestine than surface rinsing water, pond mud, and pond water samples. For instance, a high percentage and broad spectrum of AR genes were found in isolates from fish feed samples, including sul1 (10.2\%), sul2 (2.0\%), tet $\mathrm{L}$ (13.3\%), tet $\mathrm{M}$ (9.2\%), tet $\mathrm{S}(6.1 \%)$, and erm $\mathrm{B}(1.0 \%)$. Within the 13 AR determinants examined, tet $\mathrm{M}$ had the highest detection rate $(8.1 \%)$ in the isolates.

As illustrated in Table 4, identified AR gene carriers belonged to 18 genera. Aeromonas sp., Enterococcus sp., Enterobacter sp., and Plesiomonas sp. identified in fish intestine samples were commonly isolated from fish (Austin, 2002). Some of the isolates examined, including Bacillus sp., Carnobacterium sp., Corynebacterium sp., Enterococcus sp., Plesiomonas sp., Lactococcus sp., and Psychrobacter sp. were found to carry multiple resistance encoding genes. Fish feed contained various AR genes in a broad spectrum of organisms, though total count of ART bacteria was relatively low. 
TABLE 2 | Comparison of MIC results between BHI and CAMH medium.

\begin{tabular}{|c|c|c|c|c|c|c|c|c|c|c|}
\hline \multirow[t]{3}{*}{ Isolates } & \multirow[t]{3}{*}{ Identity } & \multirow[t]{3}{*}{ AR genes carried } & \multicolumn{8}{|c|}{ Resistance phenotype and MIC $(\mu \mathrm{g} / \mathrm{ml})$} \\
\hline & & & \multicolumn{2}{|r|}{ Sul/Trir } & \multicolumn{2}{|c|}{ Tet $^{r}$} & \multicolumn{2}{|c|}{$\mathrm{Erm}^{\mathrm{r}}$} & \multicolumn{2}{|c|}{ Ctx ${ }^{r}$} \\
\hline & & & BHI & CAMH & BHI & CAMH & BHI & CAMH & BHI & CAMH \\
\hline 17iT21 & Plesiomonas sp. & sul1 & $>608 / 32$ & $>608 / 32$ & 256 & 128 & - & - & - & - \\
\hline 17wT9 & Plesiomonas sp. & tetM & - & - & 256 & 128 & - & - & - & - \\
\hline 18iS4 & Plesiomonas sp. & sul2 & $>608 / 32$ & $>608 / 32$ & - & - & - & - & - & - \\
\hline 18iS31 & Plesiomonas sp. & sul2 & $>608 / 32$ & $>608 / 32$ & - & - & - & - & - & - \\
\hline $17 f S 1$ & Enterococcus sp. & tetM, tetL & $>608 / 32$ & Weak growth $\leq 9.5 / 0.5$ & 256 & 128 & - & - & - & - \\
\hline $17 f S 3$ & Enterococcus sp. & sul1 & $>608 / 32$ & Weak growth $\leq 9.5 / 0.5$ & 16 & 16 & - & - & - & - \\
\hline $18 \mathrm{i} \times 15$ & Enterococcus sp. & tetS, tetL & $>608 / 32$ & Weak growth $\leq 9.5 / 0.5$ & 256 & 128 & - & - & 512 & 512 \\
\hline $18 \mathrm{TT} 19$ & Enterococcus sp. & tetS & $>608 / 32$ & Weak growth $\leq 9.5 / 0.5$ & 256 & 128 & - & - & - & - \\
\hline 17iE3 & Enterobacter sp. & sul2 & $304 / 16$ & $\leq 9.5 / 0.5$ & - & - & 512 & 256 & - & - \\
\hline 17iE10 & Enterobacter sp. & sul2 & $>608 / 32$ & $\leq 9.5 / 0.5$ & - & - & 512 & 256 & - & - \\
\hline 17iE11 & Enterobacter sp. & sul2 & $304 / 16$ & $\leq 9.5 / 0.5$ & - & - & 512 & 256 & 16 & 8 \\
\hline 17iE26 & Enterobacter sp. & sul2 & $>608 / 32$ & $\leq 9.5 / 0.5$ & - & - & 512 & 256 & - & - \\
\hline $17 f T 6$ & Kocuria sp. & sul1 & $>608 / 32$ & $\leq 9.5 / 0.5$ & 64 & 64 & - & - & - & - \\
\hline $17 f \mathrm{~T} 2$ & Corynebacterium sp. & sul1 & $>608 / 32$ & Weak growth & 256 & 128 & - & - & - & - \\
\hline $18 \mathrm{~T} 26$ & Corynebacterium sp. & tetL & - & - & 32 & 32 & - & - & - & - \\
\hline $18 \mathrm{TT} 27$ & Corynebacterium sp. & tetL & - & - & 32 & 32 & - & - & - & - \\
\hline 18iS7 & Aeromonas sp. & sul1 & $>608 / 32$ & $>608 / 32$ & - & - & - & - & - & - \\
\hline 18fE1 & Bacillus sp. & ermB & $>608 / 32$ & $\leq 9.5 / 0.5$ & 256 & 256 & 512 & 512 & 4 & 4 \\
\hline $17 f \mathrm{~T} 12$ & Aerococcus sp. & tetM & $>608 / 32$ & Weak growth & 256 & 128 & - & - & - & - \\
\hline $17 f S 5$ & Aerococcus sp. & tetM & $>608 / 32$ & Weak growth & 32 & 32 & - & - & - & - \\
\hline $18 \mathrm{fS} 13$ & Psychrobacter sp. & sul2 & $>608 / 32$ & $>608 / 32$ & 32 & 32 & - & - & - & - \\
\hline $18 f S 19$ & Psychrobacter sp. & sul1, sul2 & $>608 / 32$ & $>608 / 32$ & 32 & 32 & - & - & - & - \\
\hline 18pwE5 & Staphylococcus sp. & ermC & $>608 / 32$ & $\leq 9.5 / 0.5$ & - & - & $>512$ & $>512$ & $>512$ & $>512$ \\
\hline $18 \mathrm{TT} 47$ & Carnobacterium sp. & tetS, tetL & - & - & 64 & 64 & - & - & - & - \\
\hline $18 \mathrm{fT} 5$ & Kurthia sp. & tetM & $>608 / 32$ & $\leq 9.5 / 0.5$ & 256 & 256 & - & - & 64 & 16 \\
\hline 18 1729 & Lactobacillus sp. & tetL & - & - & 32 & 32 & - & - & - & - \\
\hline $18 f S 10$ & Pseudoclavibacter sp. & sul1 & $608 / 32$ & 608/32 & 32 & 32 & - & - & - & - \\
\hline $18 \mathrm{fT} 12$ & Vagococcus sp. & tetL & $>608 / 32$ & No growth & 128 & No growth & - & - & - & - \\
\hline
\end{tabular}

$\mathrm{BH}$, Brain heart infusion; $\mathrm{CAMH}$, cation-adjusted Mueller Hinton.

TABLE 3 | Multi-drug-resistant isolates from aquaculture samples.

\begin{tabular}{|c|c|c|c|c|}
\hline \multirow[t]{2}{*}{ Sample } & \multicolumn{4}{|c|}{ Isolates resistant to antibiotic } \\
\hline & $1 A R^{a}$ & 2AR & 3AR & 4AR \\
\hline Surface rinsing water $(n=850)$ & $18.7 \%(159 / 850)$ & $35.6 \%(303 / 850)$ & $32.2 \%(274 / 850)$ & $13.4 \%(114 / 850)$ \\
\hline Fish intestine $(n=1045)$ & $19.8 \%(207 / 1045)$ & $58.5 \%(611 / 1045)$ & $12.1 \%(126 / 1045)$ & $9.7 \%(101 / 1045)$ \\
\hline Pond mud ( $n=1293$ ) & $13.4 \%(173 / 1293)$ & $34.9 \%(451 / 1293)$ & $34.0 \%(440 / 1293)$ & $17.7 \%(229 / 1293)$ \\
\hline Pond water ( $n=1429)$ & $8.7 \%(125 / 1429)$ & $15.2 \%(217 / 1429)$ & $50.6 \%(723 / 1429)$ & $25.5 \%(364 / 1429)$ \\
\hline Fish feed $(n=150)$ & $36.0 \%(54 / 150)$ & $31.3 \%(47 / 150)$ & $22.0 \%(33 / 150)$ & $10.7 \%(16 / 150)$ \\
\hline
\end{tabular}

a Number of antibiotic(s) the isolates were resistant to.

\section{Stability of the AR}

Results of persistence assessment showed that $90-100 \%$ of the progenies from nine ART isolates examined retained their original AR traits, indicating that the AR determinants are generally stable in the resistant isolates without the corresponding antibiotic selective pressure. Progenies of an Enterococcus strain from the intestine sample retained resistance to Sur/Tri but became susceptible to Tet and Ctx.

\section{Functionality of the AR Determinants}

Plasmids from two out of nine Gram-negative isolates $\left(s u l 1^{+}\right.$ Aeromonas sp. from the fish intestine and sul2 ${ }^{+}$Psychrobacter sp. from the fish feed) and one out of five Gram-positive isolate (tet $\mathrm{L}^{+}$Vagococcus sp. from fish feed) were successfully transferred to $E$. coli and $L$. lactis, respectively, resulting in acquired resistance in transformants. The transformants exhibited comparable MIC for the corresponding antibiotic with 
TABLE 4 | The identity of AR gene carriers.

\begin{tabular}{|c|c|c|}
\hline Sample (\# isolates tested) & Detected AR genes (\# positive isolates) & Gene carrier [AR gene (\#isolates identified)] \\
\hline Surface rinsing water (209) & sul1 (8), sul2 (1), tetM (30), sul1+tetM (5) & Plesiomonas sp. [sul1 (3), sul2 (1), tetM(3), sul1+tetM (2)] \\
\hline Fish intestine (357) & sul1 (7), sul2 (15), tetL (1), tetM (9), sul1+tetM (1), tetL+tetS(1), & $\begin{array}{l}\text { Aeromonas sp. [ sul1 (1)]; Enterobacter sp., [sul2 (7)]; } \\
\text { Enterococcus sp. [tetL (1), tetL+ tetS (1)]; } \\
\text { Plesiomonas sp. [sul1 (3), sul2 (6), sul1+ tetM (1)]; }\end{array}$ \\
\hline Pond Mud (269) & sul1 (3), sul2 (1) & Aeromonas sp. [sul1 (1)]; Plesiomonas sp. [sul1 (1)] \\
\hline Pond water (244) & sul1 (5), tetS (1), tetL+tetS (3), erm C(1) & $\begin{array}{l}\text { Exiguobacterium sp. [sul1 (2)]; Staphylococcus sp. [ermC (1)]; } \\
\text { Lactococcus sp. [tetS (1), tetL+tetS (2)]; }\end{array}$ \\
\hline Fish feed (98) & $\begin{array}{l}\text { sul1 (9), sul2 (1), sul1+sul2 (1), tetL (4), tetM (2), tetS (3), tetL+tetM } \\
\text { (6), tetL+tetS (2), tet } \mathrm{L}+\text { tetM+tetS (1), ermB (1) }\end{array}$ & $\begin{array}{l}\text { Aerococcus sp. [tetM (2)]; Bacillus sp. [tetS (1), ermB (1)]; } \\
\text { Carnobacterium sp. [tetL+tetS (1)]; } \\
\text { Corynebacterium sp. [sul1 (1), tetL (2)]; Kurthia sp. [tetM (1)]; } \\
\text { Enterococcus sp. [sul1 (1), tetS (2), tetL+tetM (5), tetL+tetS (1), } \\
\text { tetL+tetM+tetS (1)]; Kocuria sp. [sul1 (4)]; Lactobacillus sp. [tetL } \\
\text { (1)]; Pseudoclavibacter sp. [sul1 (1)]; } \\
\text { Psychrobacter sp. [sul2 (1), sul1+sul2 (1)]; } \\
\text { Staphylococcus sp. [sul1 (1)]; Vagococcus sp. [ tetL (1)] }\end{array}$ \\
\hline
\end{tabular}

the donors, indicating the resistance genes were functional in other bacteria if acquired via horizontal gene transfer events.

\section{Discussion}

It is recognized that $\mathrm{AR}$ ecology, of the emergence, persistence, and dissemination of ART bacteria and AR genes in the microbial ecosystem, is much more complicated than previously thought. Up to $10^{7} \mathrm{CFU} / \mathrm{g}$ ART bacteria, representing about $1 \%$ of the total bacterial population, were detected in the samples from this aquaculture farm, despite that the farm has no known history of antibiotic applications during production (Huang, 2014). Here, we report that majority of the ART isolates from the fish and aquaculture environment were resistant to two or more antibiotics.

MIC is a relatively precise measure of resistance to antibiotics. The measurement is essential for AR assessment not just because of the need to measure resistance trend, but more importantly, the MIC value is correlated to the dosage required for effective therapy. It is important to recognize that bacterial strains carrying the same resistance gene may have different MIC values, even for those from the same genus (Miranda et al., 2003). Understanding the molecular mechanisms contributing to the phenotype would be of great value to properly evaluate $\mathrm{AR}$ risk and control its dissemination. However, it has been difficult to compare antibiotic susceptibility results because of variation in testing methods in published studies. Most studies in the United States used CAMH broth, following NCCLS-recommended procedure (now it is CLSI), while Iso-Sensitest broth is widely used in Europe (Koeth et al., 2000). Koeth et al. (2000) conducted a study using 124 Centers for Disease Control and Prevention (CDC) reference strains compared the medium effect on MIC results, and concluded that data from the above two broth were comparable.

Due to genetic diversity of microbiota associated with both host and natural environment, bacterial media used in the studies likely have an impact on the results. Sul/ $\operatorname{Tri}^{\mathrm{r}}$ population was found abundant in microbiota across the host and environmental samples. Considering the potential effect of cultural medium on MIC results, in this study we have examined MIC for representative strains in both $\mathrm{CAMH}$ and $\mathrm{BHI}$. The isolates had different MIC values in the two media, especially for Sul/Tri ${ }^{\mathrm{r}}$ isolates. Approximately $67 \% \mathrm{Sul} / \mathrm{Tri}^{\mathrm{r}}{ }$ isolates recovered from $\mathrm{BHI}$ medium exhibited resistance against Sul/Tri in CAMH medium (data no shown), and some of them had much higher MIC values in BHI than that in CAMH. As shown in Table 2, some isolates such as Enterococcus sp. (17fS1, 17fS3, 18iX15, and 18fT19) and Enterobacter sp. (17iE3, 17iE10, 17iE11, and 17iE26) were classified as susceptible to Sul/Tri using CAMH, but showed high MIC values in BHI. In fact, the corresponding resistance determinants sul 1 or sul 2 were identified in the above strains with positive detection rate comparable to other AR genes, suggesting their MIC results in CAMH-Sul/Tri broth cannot represent their real resistance status against the antibiotics. As a matter of fact, CLSI has acknowledged the mismatch between MIC results of Enterococcus sp. using CAMH-Sul/Tri medium and resistant patterns in clinical treatments (CLSI, 2013). Moreover, although CAMH medium is widely used for MIC test, bacteria from certain genera didn't grow well in CAMH. As shown in Table 2, one tet $\mathrm{L}$ bearing isolate Vagococcus sp. could not grow in CAMH-Tet, but showed high MIC value $(128 \mu \mathrm{g} / \mathrm{ml})$ in BHI-Tet. These data indicated the limitations of $\mathrm{CAMH}$ as the medium for MIC assessment. While we have found that BHI serves the need for MIC analysis for most of the commensal isolates in this study, further validation using more reference strains and supplementation of media for cultures discriminated by BHI will be essential for methodology improvement. Moreover, ART isolates with higher MIC values are more difficult to eliminate with antibiotics. Whether the high MICs of the above strains are due to new molecular determinants or established resistance genes but with additional enhancement mechanisms are worth further investigation.

As illustrated in Table 4, 30 of 98 ART isolates (30.6\%) from fish feed samples were found to carry one or more of the 12 AR genes examined, and the positive detection rate was much 
higher than those of the ART isolates from other samples, being $9.5 \%$ (34 of 357) in fish intestine, $21 \%$ (44 of 209) in surface rinsing water associated with skin microbiota, 4.1\% (10 of 244) in pond water, and $1.5 \%$ (4 of 269) in pond mud sample. This result was consistent with the finding that multiple AR gene pools in high levels were detected in fish feed samples by real-time PCR (Huang, 2014). In addition, fish skin and intestine samples also contained a large number of ART bacteria and AR genes which also is in agreement with the results reported by Ye et al. (2013). Because animal and fish by-products, often rich in ART bacteria, are used in fish feed as an important protein source, it is inevitable that there is a large pool of AR genes and potentially AR gene carrying bacteria in fish feed. ART bacteria even multidrug-resistant bacteria were reported in various types of animal feeds, such as poultry feeds (Schwalbe et al., 1999), cattle feed ingredients (Dargatz et al., 2005), and rendered animal protein products originating from poultry, cattle, and fish (Hofacre et al., 2001). Without proper treatment, fish feed rich in AR gene-carrying bacteria survived the feed manufacturing process could be a potential risk factor spreading ART bacteria in the aquaculture production system and subsequently the food chain. In fact, several genera of ART bacteria were found in multiple types of samples. For example, Plesiomonas sp. were detected in surface rinsing water, fish intestine, and pond mud samples, while Aeromonas sp. were present in fish intestine and pond mud samples. The data suggested that these microorganisms were present in both the host and farm environment, and may have been circulating within the aquaculture ecosystem.

As illustrated in Table 4, there was no significant correlation of the types of AR encoding genes and their carriers between fish intestine and feed, indicating that hosts (fish) potentially also have a role in the selective enrichment of or breeding certain resistant bacteria in the population. In this study, the sul 1 gene of Aeromonas sp. from the fish intestine, the sul2 gene of

\section{References}

Akinbowale, O. L., Peng, H., Grant, P., and Barton, M. D. (2007). Antibiotic and heavy metal resistance in motile aeromonads and pseudomonads from rainbow trout (Oncorhynchus mykiss) farms in Australia. Int. J. Antimicrob. Agents 30, 177-182. doi: 10.1016/j.ijantimicag.2007. 03.012

Andremont, A. (2003). Commensal flora may play key role in spreading antibiotic resistance. ASM News 69, 601-607.

Aubry-Damon, H., Grenet, K., Sall-Ndiaye, P., Che, D., Cordeiro, E., Bougnoux, M. E., et al. (2004). Antimicrobial resistance in commensal flora of pig farmers. Emerg. Infect. Dis. 10, 873-879. doi: 10.3201/eid1005. 030735

Austin, B. (2002). The bacterial microflora of fish. Sci. World J. 2, 558-572. doi: $10.1100 /$ tsw.2002.137

Bhullar, K., Waglechner, N., Pawlowski, A., Koteva, K., Banks, E. D., Johnston, M. D., et al. (2012). Antibiotic resistance is prevalent in an isolated cave microbiome. PLoS ONE 7:e34953. doi: 10.1371/journal.pone. 0034953

Budiati, T., Rusul, G., Wan-Abdullah, W. N., Arip, Y. M., Ahmad, R., and Thong, K. L. (2013). Prevalence, antibiotic resistance and plasmid profiling of Salmonella in catfish (Clarias gariepinus) and tilapia (Tilapia mossambica) obtained from wet markets and ponds in Malaysia. Aquaculture 37, 127-132. doi: 10.1016/j.aquaculture.2012.11.003
Psychrobacter sp. and the tet (L) gene of Vagococcus sp. from the fish feed were found functional after being transferred to the corresponding recipients, suggesting that they can serve as a source of AR genes if involved in horizontal gene transfer events. Finally, representative AR genes were only found in a small percent of the ART isolates. A functional genomic analysis has already discovered a new $\operatorname{Tet}^{\mathrm{r}}$-encoding gene, tet47, from a $\mathrm{Tet}^{\mathrm{r}}$ isolate associated with a fish intestine sample (Huang et al., 2015).

In summary, ART commensal bacteria associated with this aquaculture system with no known history of antibiotics application exhibited multi-drug-resistance (MDR). Various AR determinants were detected and 18 bacterial genera were identified among those AR gene carrying isolates. The data suggested that the aquaculture system is a rich reservoir of $A R$, risk factors other than direct antibiotic application, such as AR-rich feed or even environmental factors, may have played important role(s) disseminating AR in this ecosystem. Followup studies are needed to reveal a more comprehensive picture of $\mathrm{AR}$ in aquaculture production, and for targeted and effective AR mitigation in the ecosystem. Moreover, BHI medium was found more suitable for majority of the commensal bacteria examined than CAMH broth for MIC assessment.

\section{Acknowledgments}

This study is supported by Ohio Soybean Council (RF project 60031678), U.S.-UK Global Innovation Initiative Award by Institute of International Education, U.S. Department of State (RF project 60043259), and State and federal funds appropriated to The Ohio State University, Ohio Agricultural Research and Development Center (project OHOA1006). Chinese Scholarship Council provided stipend support for $\mathrm{YH}$.

CLSI. (2013). Perfomance Standars for Antimicrobial Susceptibility Testing; TwentyThird Informational Supplement. Wayne, PA: Clinical and Laboratory Standards Institue.

Dagert, M., and Ehrlich, S. D. (1979). Prolonged incubation in calcium chloride improves the competence of Escherichia coli cells. Gene 6, 23-28. doi: 10.1016/0378-1119(79)90082-9

Dallenne, C., Da Costa, A., Decré, D., Favier, C., and Arlet, G. (2010). Development of a set of multiplex PCR assays for the detection of genes encoding important $\beta$-lactamases in Enterobacteriaceae. J. Antimicrob. Chemother. 65, 490-495. doi: 10.1093/jac/dkp498

Dargatz, D. A., Strohmeyer, R. A., Morley, P. S., Hyatt, D. R., and Salman, M. D. (2005). Characterization of Escherichia coli and Salmonella enterica from cattle feed ingredients. Foodborne Pathog. Dis. 2, 341-347. doi: 10.1089/fpd.2005.2.341

D’Costa, V. M., King, C. E., Kalan, L., Morar, M., Sung, W. W., Schwarz, C., et al. (2011). Antibiotic resistance is ancient. Nature 477, 457-461. doi: 10.1038 /nature10388

Duran, G. M., and Marshall, D. L. (2005). Ready-to-eat shrimp as an international vehicle of antibiotic-resistant bacteria. J. Food Prot. 68, 2395-2401.

Hofacre, C. L., White, D. G., Maurer, J. J., Morales, C., Lobsinger, C., and Hudson, C. (2001). Characterization of antibiotic-resistant bacteria in rendered animal products. Avian Dis. 45, 953-961. doi: 10.2307/1592874

Huang, Y. (2014). Antibiotic Resistance in Aquaculture Production. Ph.D. dissertation, The Ohio State University, Columbus, $\mathrm{OH}$. 
Huang, Y., Zhang, L., and Wang, H. H. (2015). Identification of a new tetracycline resistance determinant tet47 from fish intestine. J. Food Prot. 78, 1581-1585. doi: 10.4315/0362-028X.JFP-15-025

Kerrn, M. B. (2002). Susceptibility of Danish Escherichia coli strains isolated from urinary tract infections and bacteraemia, and distribution of sul genes conferring sulphonamide resistance. J. Antimicrob. Chemother. 50, 513-516. doi: $10.1093 /$ jac/dkf164

Koeth, L. M., King, A., Knight, H., May, J., Miller, L. A., Phillips, I., et al. (2000). Comparison of cation-adjusted Mueller-Hinton broth with Iso-Sensitest broth for the NCCLS broth microdilution method. J. Antimicrob. Chemother. 46, 369-376. doi: 10.1093/jac/46.3.369

Koike, S., Krapac, I. G., Oliver, H. D., Yannarell, A. C., Chee-Sanford, J. C., Aminov, R. I., et al. (2007). Monitoring and source tracking of tetracycline resistance genes in lagoons and groundwater adjacent to swine production facilities over a 3-year period. Appl. Environ. Microbiol. 73, 4813-4823. doi: 10.1128/AEM.00665-07

Li, X., Alvarez, V., Harper, W. J., and Wang, H. H. (2011). Persistent, toxinantitoxin system-independent, tetracycline resistance-encoding plasmid from a dairy Enterococcus faecium isolate. Appl. Environ. Microbiol. 77, 7096-7103. doi: 10.1128/AEM.05168-11

Li, X., and Wang, H. H. (2010). Tetracycline resistance associated with commensal bacteria from representative ready-to-consume deli and restaurant foods. J. Food Prot. 73, 1841-1848.

Manuzon, M. Y., Hanna, S. E., Luo, H., Yu, Z., Harper, W. J., and Wang, H. H. (2007). Quantitative assessment of the tetracycline resistance gene pool in cheese samples by real-time TaqMan PCR. Appl. Environ. Microbiol. 73, 1676-1677. doi: 10.1128/AEM.01994-06

McIntosh, D., Cunningham, M., Ji, B., Fekete, F. A., Parry, E. M., Clark, S. E., et al. (2008). Transferable, multiple antibiotic and mercury resistance in Atlantic Canadian isolates of Aeromonas salmonicida subsp. salmonicida is associated with carriage of an IncA/C plasmid similar to the Salmonella enterica plasmid pSN254. J. Antimicrob. Chemother. 61, 1221-1228. doi: 10.1093/jac/dkn123

Mcintyre, D. A., and Harlander, S. K. (1989). Improved electroporation efficiency of intact Lactococcus lactis subsp. lactis cells grown in defined mediat. Appl. Environ. Microbiol. 55, 2621-2626.

Miranda, C. D., Kehrenberg, C., Ulep, C., Schwarz, S., and Roberts, M. C. (2003). Diversity of tetracycline resistance genes in bacteria from Chilean salmon farms. Appl. Environ. Microbiol. 47, 883-888.

Oh, E. G., Son, K. T., Yu, H., Lee, T. S., Lee, H. J., Shin, S., et al. (2011). Antimicrobial resistance of Vibrio parahaemolyticus and Vibrio alginolyticus strains isolated from farmed fish in Korea from 2005 through 2007. J. Food Prot. 74, 380-386. doi: 10.4315/0362-028X.JFP-10-307

Österblad, M., Norrdahl, K., Korpimäki, E., and Huovinen, P. (2001). How wild are wild mammals? Nature 409, 37-38. doi: 10.1038/35051173

Penders, J., and Stobberingh, E. E. (2008). Antibiotic resistance of motile aeromonads in indoor catfish and eel farms in the southern part of the Netherlands. Int. J. Antimicrob. Agents 31, 261-265. doi: 10.1016/j.ijantimicag.2007.10.002

Rebouças, R. H., de Sousa, O. V., Lima, A. S., Vasconcelos, F. R., de Carvalho, P. B., Vieira, R. H. S., et al. (2011). Antimicrobial resistance profile of Vibrio species isolated from marine shrimp farming environments (Litopenaeus vannamei) at Ceará, Brazil. Environ. Res. 111, 21-24. doi: 10.1016/j.envres.2010.09.012

Rhodes, G., Huys, G., Swings, J., Mcgann, P., Hiney, M., Smith, P., et al. (2000). Distribution of oxytetracycline resistance plasmids between aeromonads in hospital and aquaculture environments: implication of Tn 1721 in dissemination of the tetracycline resistance determinant Tet A. Appl. Environ. Microbiol. 66, 3883-3890. doi: 10.1128/AEM.66.9.3883-3890.2000

Ribeiro, R. V., Reis, E. M. F., Reis, C. M. F., Freitas-Almeida, A. C., and Rodrigues, D. P. (2010). Incidence and antimicrobial resistance of enteropathogens isolated from an integrated aquaculture system. Lett. Appl. Microbiol. 51, 611-618. doi: 10.1111/j.1472-765X.2010.02946.x
Rosvoll, T. C. S., Pedersen, T., Sletvold, H., Johnsen, P. J., Sollid, J. E., Simonsen, G. S., et al. (2010). PCR-based plasmid typing in Enterococcus faecium strains reveals widely distributed pRE25-, pRUM-, pIP501- and pHTbeta-related replicons associated with glycopeptide resistance and stabilizing toxin-antitoxin systems. FEMS Immunol. Med. Microbiol. 58, 254-268. doi: 10.1111/j.1574695X.2009.00633.x

Schwalbe, R. S., McIntosh, A. C., Qaiyumi, S., Johnson, J. A., and Morris, J. G. (1999). Isolation of vancomycin-resistant enterococci from animal feed in USA. Lancet 353, 722. doi: 10.1016/S0140-6736(98) 05441-5

Shah, S. Q. A., Cabello, F. C., L’abée-Lund, T. M., Tomova, A., Godfrey, H. P., Buschmann, A. H., et al. (2014). Antimicrobial resistance and antimicrobial resistance genes in marine bacteria from salmon aquaculture and nonaquaculture sites. Environ. Microbiol. 16, 1310-1320. doi: 10.1111/14622920.12421

Sommer, M. O. A., Dantas, G., and Church, G. M. (2009). Functional characterization of the antibiotic resistance reservoir in the human microflora. Science 325, 1128-1131. doi: 10.1126/science. 1176950

Sørum, M., Johnsen, P. J., Aasnes, B., Rosvoll, T., Kruse, H., Sundsfjord, A., et al. (2006). Prevalence, persistence, and molecular characterization of glycopeptideresistant enterococci in Norwegian poultry and poultry farmers 3 to 8 years after the ban on avoparcin. Appl. Environ. Microbiol. 72, 516-521. doi: 10.1128/AEM.72.1.516-521.2006

Venter, J. C., Remington, K., Heidelberg, J. F., Halpern, A. L., Rusch, D., Eisen, J. A., et al. (2004). Environmental genome shotgun sequencing of the Sargasso Sea. Science 304, 66-74. doi: 10.1126/science.1093857

Wang, H. H., Manuzon, M., Lehman, M., Wan, K., Luo, H., Wittum, T. E., et al. (2006). Food commensal microbes as a potentially important avenue in transmitting antibiotic resistance genes. FEMS Microbiol. Lett. 254, 226-231. doi: 10.1111/j.1574-6968.2005.00030.x

Wang, H. H., and Schaffner, D. W. (2011). Antibiotic resistance: how much do we know and where do we go from here? Appl. Environ. Microbiol. 77, 7093-7095. doi: 10.1128/AEM.06565-11

Ye, L., Lu, Z., Li, X., Shi, L., Huang, Y., and Wang, H. H. (2013). Antibiotic-resistant bacteria associated with retail aquaculture products from Guangzhou, China. J. Food Prot. 76, 295-301. doi: 10.4315/0362-028X.JFP12-288

Zhanel, G. G., Karlowsky, J. A., Harding, G. K. M., Carrie, A., Mazzulli, T., Low, D. E., et al. (2000). A Canadian national surveillance study of urinary tract isolates from outpatients: comparison of the activities of trimethoprimsulfamethoxazole, ampicillin, mecillinam, nitrofurantoin, and ciprofloxacin. Antimicrob. Agents Chemother. 44, 1089-1092. doi: 10.1128/AAC.44.4.10891092.2000

Zhang, L. (2011). Establishment and Development of Antibiotic Resistant Bacteria in Host Gastrointestinal Tract-Food, Drug, or are We Born with It? Ph.D. dissertation, The Ohio State University, Columbus, $\mathrm{OH}$.

Zhang, L., Kinkelaar, D., Huang, Y., Li, Y., Li, X., and Wang, H. H. (2011). Acquired antibiotic resistance: are we born with it? Appl. Environ. Microbiol. 77, 7134-7141. doi: 10.1128/AEM.05087-11

Conflict of Interest Statement: The authors declare that the research was conducted in the absence of any commercial or financial relationships that could be construed as a potential conflict of interest.

Copyright (c) 2015 Huang, Zhang, Tiu and Wang. This is an open-access article distributed under the terms of the Creative Commons Attribution License (CC BY). The use, distribution or reproduction in other forums is permitted, provided the original author(s) or licensor are credited and that the original publication in this journal is cited, in accordance with accepted academic practice. No use, distribution or reproduction is permitted which does not comply with these terms. 